\title{
Imagining the unimaginable: synthesis of essays on abrupt and extreme climate change
}

Citation for published version (APA):

Martens, P., Aerts, J. C. J. H., Amelung, B., Bouwer, L. M., Chang, C. T., Huynen, M., van lerland, E. C., van Koppen, C. S. A., McEvoy, D., Mol, A. P. J., \& van Tatenhove, J. (2010). Imagining the unimaginable: synthesis of essays on abrupt and extreme climate change. Current Opinion in Environmental

Sustainability, 2(5-6), 347-355. https://doi.org/10.1016/j.cosust.2010.10.005

Document status and date:

Published: 01/12/2010

DOI:

10.1016/j.cosust.2010.10.005

Document Version:

Publisher's PDF, also known as Version of record

Document license:

Taverne

Please check the document version of this publication:

- A submitted manuscript is the version of the article upon submission and before peer-review. There can be important differences between the submitted version and the official published version of record.

People interested in the research are advised to contact the author for the final version of the publication, or visit the DOI to the publisher's website.

- The final author version and the galley proof are versions of the publication after peer review.

- The final published version features the final layout of the paper including the volume, issue and page numbers.

Link to publication

\footnotetext{
General rights rights.

- You may freely distribute the URL identifying the publication in the public portal. please follow below link for the End User Agreement:

www.umlib.nl/taverne-license

Take down policy

If you believe that this document breaches copyright please contact us at:

repository@maastrichtuniversity.nl

providing details and we will investigate your claim.
}

Copyright and moral rights for the publications made accessible in the public portal are retained by the authors and/or other copyright owners and it is a condition of accessing publications that users recognise and abide by the legal requirements associated with these

- Users may download and print one copy of any publication from the public portal for the purpose of private study or research.

- You may not further distribute the material or use it for any profit-making activity or commercial gain

If the publication is distributed under the terms of Article $25 \mathrm{fa}$ of the Dutch Copyright Act, indicated by the "Taverne" license above, 


\section{Imagining the unimaginable: synthesis of essays on abrupt and extreme climate change}

Pim Martens ${ }^{1}$, Jeroen CJH Aerts ${ }^{2}$, Bas Amelung ${ }^{3}$, Laurens M Bouwer ${ }^{2}$, Chiung Ting Chang ${ }^{4}$, Maud Huynen ${ }^{4}$, Ekko $\mathrm{C}$ van lerland ${ }^{5}$, CSA (Kris) van Koppen ${ }^{6}$, Darryn McEvoy ${ }^{7}$, Arthur PJ Mol${ }^{6}$ and Jan van Tatenhove ${ }^{6}$

With a shutdown or slowdown of the oceanic thermohaline circulation, which acts as a conveyor belt that transports warmer waters northwards to the maritime regions of Western Europe, many parts of Europe could face abrupt decreases in temperature, with potentially serious social and economic consequences. What do we know about the potential impacts and society's vulnerability to them, how can we best prepare, and what is the cost of action likely to be? How well prepared are we for abrupt and extreme climate change? This paper reflects on five essays, each looking at the issue through a different lens: legal, institutional, sectoral, multi-sectoral, and economic.

\footnotetext{
Addresses

${ }^{1}$ ICIS, Maastricht University, PO Box 616, 6200 MD Maastricht, Netherlands \& Department of Sustainability Sciences, Leuphana University Lüneburg, Germany

${ }^{2}$ IVM, VU University Amsterdam, Netherlands

${ }^{3}$ Environmental Systems Analysis Group, Wageningen University, Netherlands

${ }^{4}$ ICIS, Maastricht University, Netherlands

${ }^{5}$ Environmental Economics and Natural Resources Group, Wageningen University, Netherlands

${ }^{6}$ Environmental Policy Group, Wageningen University, Netherlands

${ }^{7}$ RMIT University, Melbourne, Australia

Corresponding author: Martens, Pim

(p.martens@maastrichtuniversity.nl)
}

Current Opinion in Environmental Sustainability 2010, 2:347-355

This review comes from the Open issue

Edited by Rik Leemans and Anand Patwardhan

Received 28 June 2010; Accepted 13 October 2010

Available online 11th November 2010

$1877-3435 / \$$ - see front matter

(C) 2010 Elsevier B.V. All rights reserved.

DOI 10.1016/j.cosust.2010.10.005

\section{Introduction}

Climate change is likely to be one of the greatest threats facing societies in the coming decades. In response, considerable international effort - most notably represented by the Kyoto Protocol - has gone into policies that will contribute to the reduction of emissions of greenhouse gases. Climate change impacts are com- monly understood as long-term changes to weather parameters. For example, the projected increase in average summer temperatures will affect European countries later this century and this will undoubtedly have implications for socio-economic systems. However, although these trends are important to understand, it is the likely pace and intensity of climatic changes that will have the most significant social and economic consequences. Synthesising scientific output since 2007, Steffen [1] notes that not only is the rapidity of change of concern but also evidence suggests long-term feedback processes are starting to develop with potential consequences for abrupt and irreversible changes. These will ultimately drive climate-related impacts. The implications of more substantial sideswipes to human activity brought about by such low-probability, uncertain, though potentially highimpact events have received relatively little attention to date. Examples of such 'tipping elements' are destabilization of the Indian and West African monsoon system, major dieback of the Amazonian forest, melting of the C. Greenland Ice Sheet, collapse of the West Antarctic Ice Sheet, and disruption of the Atlantic Thermohaline Circulation (THC) [2].

Recognising the potential importance of these low-probability, high-impact events, the Netherlands Organisation for Scientific Research (NWO) programme Vulnerability, Adaptation and Mitigation (VAM) commissioned an explorative study of the societal effects of abrupt forms of climate change [3]. The context for these explorations could have been provided by any of the tipping elements mentioned, but one of them stood out in terms of its immediate interest for Western Europe and the Netherlands, where the VAM programme was funded: the potential disruption of the THC. This THC is driven by differences in temperature and salinity/density and acts as a conveyor belt that transports warmer waters northwards to the maritime regions of Western Europe. The climatic implications of a slowdown or collapse of the thermohaline circulation are very uncertain [4]; for northwestern Europe, the effect on temperature, for example, is projected to be -1 to $-4^{\circ} \mathrm{C}$. Hence, without this naturally occurring phenomenon, parts of Europe would be much colder than is currently the case. In case of a slowdown or shutdown of the THC, society would need to adapt to a period of rapid cooling, with potentially 
catastrophic environmental, social, and economic consequences.

Although it is extremely difficult to estimate the damage which could follow from the postulated THC collapse, especially taking into account the huge uncertainty regarding its occurrence, various authors tried to give a rough overview of its key impacts on the government, the citizens, and the various sectors of the business world. Keller et al. argued that the consequences of a THC collapse 'might include decreased oceanic carbon uptake, decreased heat and water vapour transport to Europe with concomitant climate modifications, decreased fishery and agricultural yields, increased warming in the Southern Hemisphere, as well as damages to natural ecosystems' [5]. The Natural Environment Research Council stated further in 2002 that a 'sudden strong cooling could be catastrophic for agriculture, fisheries, industry and housing as crops fail, fish stocks shift to colder-water species and heating and insulation costs rocket' [6]. Arnell et al. [7] then found that the key impacts of the THC collapse in Europe are likely to be the following: (1) major reductions in crop production, with consequent impacts on food prices, access to food, and rural economies; (2) increases in cold-related deaths and ill-health (and, at the same time, a reduced potential for disease transmission); (3) major changes in temperate and Mediterranean ecosystems and the services they provide (food, biodiversity, forest products, and recreation); (4) disruption to winter travel opportunities and increased icing of northern ports and seas; (5) requirement to refurbish infrastructure, especially in Western Europe, towards Scandinavian standards; (6) reductions in runoff and water availability in Southern Europe, and a shift from winter to spring snowmelt flooding in Western Europe; (7) reduced hydro power and wind potential, energy distribution network susceptible to freeze events; and (8) large increase in heating requirements (energy). The collapse would moreover mark a change in the economic and cultural centre of gravity of Europe, in different directions: following THC collapse the shift would be southwards, implying also a movement of populations to Southern Europe. Hulme further concludes that the economic damage caused by a THC collapse is simply assumed, and that fisheries, agriculture, wildlife and forestry are the sectors most frequently cited to undergo the adverse consequences of abrupt climate change [4].

A number of key assumptions have been given by the NWO-VAM programme committee to the writing groups on potential impacts. Temperature in north-western Europe is assumed to decrease by $3^{\circ}$ between 2015 and 2030, with no change in precipitation. In the essays summarized below, the decrease in temperature is assumed to be distributed evenly throughout the year. After 2030, temperature in the region will strongly recouple with global trends of warming again, converging with the Dutch KNMI W+ scenario by 2050. This W+ scenario represents a $2^{\circ}$ global warming by 2050 (relative to 1990 ), combined with changes in air circulation patterns in Western Europe (and the related changes in the wind). Because of these changes in air circulation, the increase in the annual average temperature is higher at $2.6^{\circ}$ in 2050 and the increase in temperature is higher in the summer months compared to the winter period $[8,9]$.

Faced with high levels of uncertainty, the challenge for each of the authors was to think 'outside the box', drawing on their expert knowledge and opinion in order to explore some of the potential socio-economic aspects of a lowprobability, high-impact event and to highlight some of the likely implications for future society.

The five essays covered a selection of legal (Bruggeman \& Peeters; Law Faculty, Maastricht University), institutional (Van Koppen, Mol \& van Tatenhove; Environmental Policy Group, Wageningen University), sectoral (Amelung, Huynen, and Martens; ICIS, Maastricht University) and economic (Van Ierland; Environmental Economics and Natural Resources Group, Wageningen University) perspectives of abrupt and extreme climate change, as well as making use of historical and non-weather analogues to explore some of the implications across multiple sectors (Aerts, Smith \& Bouwer; IVM, Free University Amsterdam). This paper reflects on each essay, synthesises their key findings, before finally elaborating on what their key messages mean for both policy and practice.

\section{Legal perspective: exploring governmental and victim responsibilities in view of abrupt climate change in North-Western Europe}

The essay by Bruggeman and Peeters reflects on the complex matter of governmental and individual responsibilities and capabilities to adapt to an abrupt and rapid change. It further describes the actors that should be politically and legally responsible for the impacts of a climate-related extreme event. At the heart of their argument is a discussion of the extent to which 'the government' (and if so, which government: national and/or European?) has a leading role to play, particularly given the uncertainties surrounding future climate risks, either directly through public intervention or indirectly by enacting policy that helps to stimulate action in the private sector. In essence the essay argues that a publicled approach is likely to prove to be the most optimal option for minimising future climate risks. This message resonates with the voices of financial institutions that have argued that governments have the ultimate responsibility to manage the risks of climate change for society in the long-term [10], especially when risks are beyond normal commercial parameters and there is a need for the provision of a safety net [11].

Embedding their analysis in a Dutch context, the authors note that although Article 21 of the Dutch Constitution 
was enacted in 1983 to address social and environmental goals there is no specific article that yet deals with climate change. Although Article 21 could be (re)-interpreted as being applicable to the emerging adaptation agenda they also suggest that it has limited 'teeth' when it comes to enforceability. This leads them to the conclusion that the Dutch Constitution implies a requirement to develop and implement an adaptation policy on behalf of government, though with some degree of discretion and a current lack of clarity with regard to enforceability.

Their commentary then turns to the different forms of intervention that are potentially available in the public arsenal. These are differentiated according to whether they are direct or indirect instruments, with planning measures cited as examples of direct intervention and taxes as indirect interventions. However, it is suggested that avoidance of top-down regulation is traditionally preferred by the Dutch Government when effective self-regulation can be stimulated by other non-regulatory measures. The authors also highlight the influential role of supranational legislation in specifically the area of environmental protection and a pressing need for multi-level integration of climate policy. Interestingly, they raise the question of how well the current focus on 'climate proofing' development in the Netherlands will perform should there be a collapse in the THC, and as a result a colder climate than is currently being prepared for. These arguments provide stark illustration of the need to ensure flexibility of both policy and practical responses, in order to avoid situations where mal-adaption may occur. Against this background, a concept of 'abrupt climate change proof' is introduced.

Although the authors place significant emphasis on the public sector for considering policies, at least strategically, they also argue for adequate accompanying checks and controls to be in place. These checks are recommended not only to reduce the risk of over-reaction on the part of any government response, but also to address potential liability. This is clearly an emerging issue as trends would suggest that damage resulting from climate change is a 'legally cognisable injury', particularly if government actors are made aware of the specific risks associated with abrupt climate change. However, the conclusions of this essay would suggest that by following a well-considered adaptation policy public bodies are not likely to be found liable for the damages incurred by affected parties.

The latter part of their essay then went on to address possible financial mechanisms which could potentially be used to support adaptation objectives from the viewpoint of potential victims, again analysing the role of government in supporting this activity. The first mechanism considered was that of liability law. In this case, it was argued that this is likely to prove a very expensive option for compensating damage incurred, though if imposed it could potentially provide a significant incentive to change undesirable behaviour. However, in their deliberations, the authors raise a very tricky question that permeates across the adaptation agenda - who pays and who benefits? The second mechanism considered was the role of the private sector in providing insurance, that is compensating economic damage post event. In this instance the authors lay out some of the main arguments for and against the insurability of climate risks. However, the discussion in this part of the essay focuses predominantly on the provision of insurance by the private sector, and what is less clear in the discussion is that variations affect insurance coverage across Europe at the current time. These differences can be categorised according to three main attributes: geographical differences relating to exposure to climate-related hazards, the role played by public and private actors (the type of set-up influencing whether premiums are provided ex ante or ex post - the Netherlands operates an institutionalised ex post system), and market penetration (for a more detailed discussion of the potential role of insurance, see [12]). The role of other financial mechanisms, commonly known as alternative risk transfer, was also scoped out for their potential to contribute to the adaptation agenda, with specific attention paid to the examples of catastrophe bonds and weather derivatives.

In the penultimate section on financial mechanisms the discussion returns to the vexed issue of the role of government in not only promoting but also ensuring the long-term sustainability of adaptation measures. It is here that the authors reflect on the tensions between the public and private sectors, with three potential categories of options spotlighted. These include government-run compensation funds (recognising that it is ultimately the taxpayer that will 'pay the bill'), public intervention in private insurance markets (concluding that there is great divergence in opinion as the effectiveness and desirability of such action), and the emergence of new public-private partnerships (seen as offering considerable potential for enhancing not only the effectiveness of insurance and other financial mechanisms but also accessibility to funds).

In their concluding section on observations and recommendations the authors set out a framework for further legal research. This framework includes four governmental responsibilities: the need for a clearly defined task regarding monitoring and research, the need for flexible policies, including avoiding mal-adaptation and mal-regulation, a right to be informed about climate information and disaster protection as a governmental task. Three citizen's responsibilities are highlighted: victim responsibility is difficult to encourage through liability, innovative ex ante compensation approaches and supporting market solutions as a key governmental adaptation measure. 


\section{Institutional perspective: coping with extreme events - institutional flocking}

Drawing upon the concept of a 'risk society' the second essay of the NWO portfolio by van Koppen, Mol \& van Tatenhove develops a conceptual model, called 'institutional flocking, for clarifying the governance structures needed to cope with extreme, abrupt, and unpredictable climate events (for a further elaboration and actualization of the model, see [13]). Taking bird flocking as a metaphor, the model of institutional flocking has three main features: (1) flexible opportunities for innovation and change; (2) rapid and pervasive processes of mutual learning; and (3) strong and institutionalized care for coherence, to bind the various parts of the 'flock'. This governance model is applied in analyzing the (potential) societal responses to abrupt climate change for the cases of urban infrastructure, rural planning, and flood protection. Each of the three cases represents a vital area of Dutch environmental policy and planning. The analysis considers the shifting distributions of risks under changing conditions, as well as the shifts in management and policy towards better adapted institutional structures.

In analyzing the potential shifts in urban infrastructure, the authors point out the large-scale and centralised nature of much of the infrastructure systems (e.g. for electricity, drinking water, gas, and sewage) in Dutch cities to date. To cope with extreme weather events, such as snow and ice, systems need to be robust - that is, able to operate under a variety of conditions - and flexible - that is, able to quickly adapt to new situations. This has significant consequences not only for the technical properties and physical lay-out of infrastructure systems but also for the design, management and back-up strategies of such systems. Drawing from past weather events across the world the authors suggest that there is a need for more decentralized systems that can more easily be coupled and decoupled, with units that are also capable of operating in stand-alone mode. Where needed, end-users should be involved in operating and maintaining such systems. At the same time, however, wide-area networks and central production facilities remain necessary for reasons of efficiency and back-up. 'Institutional flocking' in the domain of urban infrastructures, therefore, is characterized by a 'modernized mixture' of large scale, centrally planned components and decentral, small-scale components. Publicprivate cooperation will be instrumental in facilitating processes of innovation and learning. Although public bodies will continue to have key responsibilities for the provision of infrastructure, the authors foresee a future where civil society organisations are likely to play an ever increasing role, not only in co-managing infrastructure components, but also in maintaining the relations of trust needed to ensure social cohesion and cooperation of actors.

The essay's introduction to rural land use planning emphasises the complex governance arrangements that underlie the formal Dutch land use planning system. Complexity is demonstrated by tensions between national and provincial authorities over different land use issues, by policy shifts towards greater horizontal integration with increased involvement of private and civil actors in decision-making processes, and by the growing influence of high-level policy emanating from the level of the EU. Turning to the potential impacts of extreme events, it is stressed that farmers are likely to bear the brunt of any rapid changes in climatic conditions, not only because of direct climate impacts, but also because of forceful land claims from other sectors trying to cope with climate changes, such as nature conservation and water management. As it is hard to predict the challenges from abrupt climate change, rapid and flexible adaption of land use forms and distributions will be needed. To achieve this, local and context-specific innovations are vital, for example, for pest control in agriculture and for adaptive management in nature protection. At the same time, however, central direction cannot be missed, for example, in supporting farmers and in designing larger-scale ecological corridors for species migration. Institutional flocking, therefore, implies intensified cooperation across different scale levels of government, and increased networking between governmental, business and civil society actors. It also implies a close cooperation between scientific research and practical application in the field. The authors point at an existing nature management programme in which scientists and practitioners closely collaborate, to illustrate how such cooperation can be structured.

Protection against sea and riverine flooding provides the substance of the third case. The discussion opens by highlighting a shift from reliance on technological or 'hard engineering' approaches to flood protection, that is the building of dykes, which have traditionally dominated the Dutch response, to more flexible and adaptive approaches, characterized by phrases such as 'living with water' and 'giving room to the rivers'. This shift reflects an acknowledgement that it is not always possible to rely solely on engineering solutions to reduce climate risks, given the increasing levels of uncertainty and the potentially heightened frequency and intensity of extreme events. It also reflects a desire to better align water security measures with natural processes. The authors highlight the institutional challenges that go together with such flexible and adaptive approaches. Like in the two other cases, a multi-actor and multi-level institutional setting is foreseen, in which new actors enter a domain that traditionally was monopolized by specific state agencies and scientific communities. Mutual learning and collaboration between civil engineers and ecological experts, and between water authorities and affected stakeholders are key features of such a setting.

Wrapping up the cases, the authors conclude that a situation of abrupt climate change asks for significant 
institutional changes. For the Dutch society to be prepared for unpredictable and extreme climate impacts, institutional arrangements are needed with high flexibility, with the potential for rapid acceleration, and with the ability for swift changes of direction. The success of such arrangements will depend not only on the development of new flexible institutions for policy, management and scientific research, but also on the institutional capacity to invoke in the population at large a sense of solidarity, and trust that these new institutions are doing 'the right thing'.

\section{Sectoral perspective: catching a cold or enjoying the breeze? Exploring the linkages between THC collapse, human health and tourism}

The essay by Amelung, Huynen and Martens considers the implications of abrupt change for both human health (focussing on temperature related mortality, Lyme disease, and pollen allergy) and tourism (summer and winter conditions). The authors argue that the projected decrease in average temperature in the case of a THC collapse will result not only in decreasing heat-related mortality as the number of days with higher temperatures declines, but also in significantly increasing cold-related mortality. It is highly likely that the net effect of these two mechanisms will be negative in the temperate European region. Here, cold-related mortality is already higher than heat-related mortality. The result of their scenario analysis for the Netherlands shows that the $3^{\circ} \mathrm{C}$ cooling is indeed expected to result in about 5.5 thousand additional temperature-related deaths per year up to 2030. Assuming that these Dutch results can be considered more or less representative for north-western Europe as a whole, the cooling would account for thousands of additional deaths in Europe during the scenario period. However, some vector-borne, air-borne and water-borne health problems may be reduced in this cooling scenario between 2015 and 2030. For instance, the risk of Lyme infection from tick bites will likely decrease, as the abrupt cooling will reduce winter survival rates of ticks transmitting Lyme disease and will also negatively affect the length of the tick season due to cooler spring and autumn temperatures. The risk of Lyme infection will be further reduced by the decreasing popularity of outdoor recreation in a cooling climate. Additionally, the cooling might affect pollen related allergic diseases, as the pollen season is expected to start considerably later. Effects on the duration of the pollen season, the amount of pollen produced and the geographical distribution of flowering plants are also likely, but still poorly understood.

The post-2030 period will see a bounce-back in temperatures. The rapid warming will subsequently result in a decrease in temperature-related deaths, as the decrease in cold-related deaths is expected to outweigh the increase in heat-related deaths. The risk of Lyme infection will probably increase again, although in some areas it may take the tick populations some time to recover after the extended period of cold conditions. The rapid warming between 2030 and 2050 will result into forward shift in the onset of the pollen season again. The rapid cooling and subsequent rapid warming is also likely to affect the geographical distribution of flowering plants.

Addressing the second case study, tourism, the authors contend that the suitability of north-western Europe for leisure activity will deteriorate as a result of the abrupt drop in temperature. In addition, the length of the summer tourism season will shorten, and even at its height the frequency of very good days will greatly diminish. It is likely that large parts of north-western Europe will enjoy only one month (or even no months) with very good weather. For the traditional Mediterranean holiday destinations, which are thought to have a bleak prospect as a result of climate change, this may be some good news. The period of cooling experienced elsewhere may allow them additional time to adapt to the inevitable prospect of global warming.

For winter sports in the mountains and for skating, a collapse of the THC will open up new opportunities. For example, it will reverse the trend of declining frequencies of Elfstedentocht skating events in the Netherlands. In the period between 2020 and 2040, when the cold period is at its peak, conditions suitable for the Elfstedentocht event are likely to occur in most winters. Perhaps as many as 5 or 6 events might actually be organized in that period. After 2040, as winter temperatures quickly rise again, the prospects of frequent Elfstedentocht events quickly disappear again.

\section{Multi-sectoral perspective: abrupt climate change - analogies in impacts and coping mechanisms}

This essay by Aerts, Smith and Bouwer addresses the issue of abrupt climate change from a different angle than others in the NWO portfolio. In addition to a shutdown of the THC, the authors consider three additional weather and non-weather related events that could potentially lead to rapid cooling in Europe. This additional analysis of some known and potential impacts from these four events helps to provide a better understanding of some of the potential socio-economic implications of THC shutdown and to gain more insights into the possible adaptation options to cope with a rapid change to the climatic regime. The four events considered were: the Little Ice Age, a nuclear winter, cooling from aerosols, and a shutdown of the THC.

The first example considered, the Little Ice Age, was included in their assessment due to its being the only abrupt climate event that has been experienced in 
industrial times. It is estimated to have lasted from the beginning of the 14th to the middle of the 19th century, with the greatest impact occurring between 1550 and 1700. Significantly colder winters and more erratic summers were representative of this period with particularly adverse impacts on the agricultural sector and knock-on implications for food availability. Written records highlighted a fluctuation in the price of grain, which could be explained by lower temperatures for example. Hypothesising future cooling events, the authors also considered the potential and extreme impact associated with cooling that would occur in the aftermath of nuclear conflict. This cooling would be a direct consequence of the blanketing of the atmosphere with particulate matter, effectively blocking the penetration of sunlight. This represents the most extreme case of cooling, with estimates suggesting a possible drop in temperature of between 10 and $15^{\circ} \mathrm{C}$ globally, for the first year at least. Dealing with the issue of aerosols - as represented by volcanic activity - historical evidence from major events would suggest that a drop in $5^{\circ} \mathrm{C}$ is a reasonable assumption for the likely scale of impact, although this would be on a more regionalised basis. Finally, the authors put some figures to the potential reduction in temperature that would accompany an overturning of the THC. For western maritime regions, a drop of 5$10^{\circ} \mathrm{C}$ has been suggested by climate change scientists though the change would likely be tempered with distance inland.

Evidence from the Little Ice Age gives clear indication that food shortages, and as a direct consequence famine, were a major problem for many societies during this colder period. For instance, the example of Iceland, which lost half its population, is cited. However, the authors also stress that in reality the situation was more complex, with culture and economy paradoxically doing well in some parts of Europe. In fact, new climatic conditions may actually have been an important driver for changing agricultural practice, as witnessed in the Netherlands by innovations such as lay farming, reclamation technologies, the growing of animal fodder, and the cultivation of grasslands for cattle. Colonial expansion would have provided a valuable support for these changes in practice by enabling access to resources from other locations. Land productivity and famine are again identified as important impacts of both the nuclear and aerosol scenarios, with vegetative productivity likely to be particularly affected. The aftermath of a nuclear attack is obviously the most extreme event, of which a drop in temperature will be only one of a multitude of threats to human well-being. The societal and environmental impacts of changes to the THC are most resembled to the effects from Little Ice Age, with impacts rippling through a range of social and economic activity from direct impacts on agricultural production to less direct impacts such as changes to energy demand as households react to the changing climate.
Following identification of some of the likely impacts, the penultimate section of the essay then summarises some of the coping mechanisms that could be called upon by society. Those mechanisms discussed include migration (citing studies that refer to a potential depopulation of the western regions towards more favourable climatic conditions found in southern and eastern reaches), shelter (pointing to the fact that Scandinavian housing has evolved, and is well suited, to existing severe climatic conditions), transport (de-icing is common-place in many countries already though new management practices may need to be developed under colder conditions), food and water supply (storage and increased trade with other parts of the world may be needed in terms of ensuring food security, with new technologies considered to be adequate to maintain water supply under cooling conditions), energy (changes to generation and supply), health and education (a refocus by the medical services on coldrelated injuries and other medical ailments), and governance and economy (financial support and international cooperation may be necessary to address some of the resource and human issues which spill-over beyond the affected regions).

Concluding, the authors signpost the collapse of current agricultural practice as one of the important casualties of rapid cooling, although recognise that other numerous impacts will be felt across all sectors of society. Although consequences are likely to be severe in many cases they argue that Europe has a high level of adaptive capacity with considerable technological, societal and economic resources at its disposal. The ability to learn from the experiences of cold countries, in terms of both infrastructure and behaviour, will be an important component in the adaptation process, and as comes through from the writings of other essays in the NWO portfolio, foresight, planning, and flexibility of response are essential if society is to reduce the risk of socio-economic disorder and adapt to new conditions that abrupt climate change will bring.

\section{Economic perspective: the slowdown of the THC - an economic perspective on adaptation}

Economic considerations and institutional complexity formed the basis of the last essay in the portfolio. Van Ierland sets out the discussion in a context of decisionmaking under uncertainty, with explicit consideration of a process of institutional learning over time. Central to the discussion is the issue of timing of response, that is do we need to take action now and what can be done or delay the decision until more information is available; essentially a 'wait and see' approach.

For the purposes of this essay, economic implications are sketched out for a range of key sectors. These include agriculture (interestingly the analysis in this case suggests 
a much smaller impact than is alluded to in other essays), energy demand and supply (likely changes in winter and summer demand are highlighted), water management (safety considered to be of paramount importance with cooling), transportation (cold weather impacting on the demand for all types of transport), tourism and recreation (shift in holiday patterns with implications for the Dutch visitor economy), health (extreme cold posing particular risks for vulnerable groups such as the elderly or homeless people), immigration/emigration (climate refugees and an internal movement of people within the EU), and ecosystems (change to growing seasons). The decrease in temperature will most likely pose costs to each of these sectors, financially, socially and environmentally.

Given the uncertainties of climate change in north-western Europe it is particularly interesting to focus on no regret strategies (i.e. strategies that actually have positive net benefits just by themselves), or strategies that will be robust (i.e. strategies that will do a good job, whether it is getting warmer or getting colder). An example of a robust strategy is better insulation of houses, factories and offices. This makes it possible to control the interior climate more efficiently, either by heating or by cooling. The optimal strategy is to choose the best sequence of policy options that can accommodate the impacts of climate change, under different possible states (e.g. warmer or colder) of the world. Over time we will learn which of the various states of the climate actually materialises: if we overreact, we will face excessive cost in terms of adaptation measures, if we do not act strongly enough we will face excessive damages.

The author contends that there is sufficient time to adjust to many of the impacts that may result from the slowdown of the THC. Van Ierland argues that there is no need for making excessive outlay now. That said, it is argued that attention should be paid to enhancing robustness to better cope with the extended thresholds induced by an abrupt decrease in temperature. This will ultimately require an integrated approach due to linkages, and potential spillover effects between sectors. One such example is better insulation of houses, factories and offices. This makes the control of the interior climate more efficient, either by heating or by cooling (possibly much can be learned from construction experience in Scandinavian countries). The challenge is not only to design buildings for internal human comfort but also to ensure that any mechanical operation is generated either by a minimum of energy requirement or by sustainable energy sources. A comfortable indoor temperature will also reduce the health risk faced by the most vulnerable groups like the elderly.

Although not discussed in any great detail in the essay, the impact on ecosystems is likely to be of great importance, again with cross-sectoral implications (e.g. affecting tourism and agriculture). Identifying and better understanding these linkages will be a significant step in moving towards a more informed adaptation response. Developing and introducing new concepts for spatial planning and the design of infrastructure and cities for instance, highlighted by the author in the introduction, are likely to be critical components of any strategic adaptation strategy.

\section{Some reflections and implications for policy and practice}

By 'imagining the unimaginable' the portfolio of VAM essays has provided multi-disciplinary insights into the potential consequences of a western maritime Europe which cools abruptly as a result of a shutdown of the THC, even at the same time that warming occurs globally. Although each of the essays explored different aspects of abrupt change from a range of perspectives there are some key generic messages that can be distilled from across the narratives.

The first common thread is that abrupt climate change will result in significant social and economic impacts for society. The complex nature of impacts will be further complicated by the fact that climate-related risks, and opportunities for adaptation, will be unevenly spread across different communities, sectors and landscape types. Agricultural practice, for example, was identified as particularly vulnerable by several essays. Furthermore, many impacts will not be confined by geographical boundaries and trans-national issues such as migration and water availability are likely to figure prominently. Improving our understanding of climate risks across sectors and spatial scales will be critical to underpinning a sustainable transition to a system that is well adapted to new climatic conditions (though it is important to note that climate change is only one risk amongst many that future societies are likely to face, and hence need to adapt to). These risks are not only diffuse and multi-scalar in nature but also in many cases adaptation will also need to account for other complexities. For example, in the case of cities, the socio-physical interactions of urban systems which are shaped by many different elements at risk and affected actors with competing priorities, will also need to be accounted for $\left[14,15^{\circ}\right]$.

Secondly, although the findings suggest considerable disruption to socio-economic systems, all note that a high level of uncertainty is involved, both in terms of likely impacts and how best to respond. In urban areas should planners and urban designers be preparing for warming or cooling? What are the implications of this for building regulations and guidance? In rural areas which crops should farmers be planting to best cope with future conditions? Improving decision-making under conditions of uncertainty will be vital if the necessary adaptation is to occur, and mal-adaptation is to be avoided. The challenges for policy-making are considerable, especially bearing in mind the fact that decisions are often framed 
by short-term election cycles and based on variables that are much more certain than is the case with the risks associated with low-probability, high-impact abrupt change. Even though this complexity makes it challenging to have adequate confidence in making informed decisions, knowledge needs to be drawn from all available quarters, including from local experience and on contributions from different parts of civil society. Speaking a common language, translating scientific information into usable knowledge, and bridging between different actors, organisations, sectors and regions will all be needed.

The VAM narratives also highlight two inter-related solutions: in the first instance the need for adaptation responses to be 'flexible' and secondly that adaptation should be understood as an iterative learning process on behalf of institutions and individuals, not merely an endpoint. Indeed, it has been recognised in the wider academic literature that an iterative learning approach is vital for addressing the uncertainties associated with climate change and variability. This represents a shift from traditional techno-centric responses to weather-related extreme events to one where flexibility, and responses that are 'fit for purpose', are considered more appropriate for dealing with the complexity of climate change [16]. Others emphasise adaptation as a response to an 'unbounded problem', where: (1) there is no clear agreement about what exactly the problem is; (2) there is uncertainty and ambiguity as to how improvements might be made; and (3) the problem has no limits in terms of the time and resources it could absorb [17]. In this sense, learning is needed to coordinate particular collective courses of action, under conditions of uncertainty, in order to achieve desirable outcomes for society. Ultimately, what will be required are adaptation measures that have the flexibility to cope with a wide range of climatic conditions.

As recognised by several of the essays, learning and better informed decision-making is supported by transference of knowledge. Although a degree of caution needs to be exercised when considering spatial analogues, it was suggested that countries such as the Netherlands could learn from the vernacular architecture and house building techniques employed by colder Scandinavian countries. It has also been recognised elsewhere that as demands for adaptation are increasingly mainstreamed, cities will increasingly act as 'laboratories' of experimentation as niches develop and innovation occurs. This practical evidence will have considerable added value if shared - raising the critical issue of knowledge transfer platforms. These, along with suitable networking forums will be an essential component of building adaptive capacity. To be effective these need to be targeted and accessible for specific end-users, not only focusing on individual sectors but also acting as a mechanism that helps to bridge across the agendas of different policy and practitioner communities [18].
Insights from all the essays reinforce the need to understand that adaptation can manifest itself in many forms: technological (including both hard and soft engineering), best practice in management, planning and design, legal responsibility and regulation, insurance, financial arrangement, or other institutional aspects. Adaptation is therefore both process and outcome. In these narratives particular importance was placed on the institutional dimension when thinking about adaptive responses to abrupt climate change. This includes issues relating to the roles and responsibilities of governments and citizens, the complexity of multi-actor and multilevel interactions, distributional effects within and across sectors, uncertainty of economic and social implications, to name but a few of the many challenges that will need to be faced under abrupt and extreme climate change.

\section{Acknowledgements}

This paper is written as part of the Dutch NWO-funded VAM programme (Vulnerability, Adaptation, Mitigation and Adaptation-Mitigation). Thanks go to all essay-authors that contributed one way or the other to this paper.

\section{References and recommended reading}

Papers of particular interest, published within the period of review, have been highlighted as:

- of special interest

•• of outstanding interest

1. Steffen W: Climate Change 2009: Faster Change and More Serious Risks Canberra, Australia: Australian Department of Climate Change; 2009.

2. Lenton T, Held H, Kriegler E, Hall J, Lucht W, Rahmstorf S: Tipping elements in the Earth's climate system. PNAS 2008, 105:1786-1793.

3. NWO: What if Abrupt and Extreme Climate Change? The Hague The Netherlands: NWO; 2008 http://www.nwo.nl/nwohome.nsf/ pages/NWOA_7M2CQB_Eng.

4. Hulme M: Abrupt climate change: can society cope? Philosophical Transactions of the Royal Society 2003, 361:2001-2021.

5. Keller K, Tan K, Morel FMM, Bradford DF: Preserving the ocean circulation: implications for climate policy. Climatic Change 2000, 47:17-49.

6. NERC: Rapid Climate Change: Thematic Research Programme Swindon: Natural Environment Research Council; 2002.

7. Arnell $\mathrm{N}$ et al.: Vulnerability to Abrupt Climate Change in Europe. Technical Report 34. Tyndall Centre for Climate Change Research; 2005.

8. The KNMI transformation and climate scenarios pages. From http://climexp.knmi.nl/Scenarios_monthly/ and http:// www.knmi.nl/klimaatscenarios/knmi06/index.html (retrieved 04.08.07).

9. Van den Hurk B, Klein Tank A, Lenderink G, Van Ulden A Van Oldenborgh GJ, Katsman C, Van den Brink H, Keller F, Bessembinder J, Burgers G et al.: KNMI Climate Change Scenarios 2006 for the Netherlands. De Bilt: The Royal Meteorological Institute for the Netherlands (KNMI); 2006.

10. Association of British Insurers: Financial Risks of Climate Change. London: ABI; 2005.

11. UNEP Finance Initiative: CEO Briefing-Adaptation and vulnerability to climate change: the role of the financial sector. 2006. 
12. Botzen WJW, Van den Bergh JCJM, Bouwer LM: Climate change and increased risk for the insurance sector: a global perspective and an assessment for the Netherlands. Natural Hazards 2010, 52:577-598.

13. Van Koppen CSA, Mol APJ, Van Tatenhove J: Coping with extreme climate events: institutional flocking. Futures 2010, 42:749-758.

14. Martens $P, M c E v o y ~ D$, Chang $C$ : The climate change challenge: linking vulnerability, adaptation, and mitigation. Curr Opin Environ Sustainab 2009, 1:1-5.

15. Martens $P$, Chang $C$ (Eds): The Social and Behavioural Aspects of

- Climate Change: Linking Vulnerability, Adaptation and Mitigation. Sheffield: Greenleaf Publishing; 2010.

This book argues that the inherent complexity of climate change will ultimately require a much more integrated response both scientifically -

to better understand multiple causes and impacts - as well as at the scientific/policy interface, where new forms of engagement between scientists, policy-makers and wider stakeholder groups can make a valuable contribution to more informed climate policy and practice. A critical element in responding to the climate change challenge will be to ensure the translation of these new scientific insights into innovative policy and practice 'on the ground'.

16. Pahl-Wostl C, Craps M, Dewulf A, Mostert E, Tabara D, Taillieu T: Social learning and water resources management. Ecol Soc 2007, 12:5.

17. Chapman J: System Failure: Why Governments Must Learn to Think Differently London: Demos; 2002.

18. McEvoy D, Lonsdale K, Rawlins J, Lindley S, Nickson A, Hinkel J, Falaleeva M.: Adaptation in the urban environment: a story of process and outcome. Journal of Environmental Planning and Management, forthcoming. 